\title{
Toxoplasma gondii prevalent in China induce weaker apoptosis of neural stem cells C17.2 via endoplasmic reticulum stress (ERS) signaling pathways
}

Jie Zhou ${ }^{1,2+}$, Xiaofeng Gan ${ }^{1 \dagger}$, Yongzhong Wang ${ }^{3,4}$, Xian Zhang ${ }^{1}$, Xiaojuan Ding ${ }^{1}$, Lingzhi Chen ${ }^{1}$, Jian Du ${ }^{5}$, Qingli Luo ${ }^{1}$, Teng Wang ${ }^{1,6}$, Jilong Shen ${ }^{1}$ and Li Yu ${ }^{1 *}$

\begin{abstract}
Background: Toxoplasma gondii, an obligate intracellular pathogen, has a strong affinity for the nervous system. TgCtwh3, a representative Chinese 1 Toxoplasma strain prevalent in China, has the polymorphic features of the effectors ROP16 $\left.\right|_{\mid / \| I}$ with type I and GRA15 || with type II Toxoplasma strains. The interaction of this atypical strain with host cells remains extremely elusive.

Methods: Using a transwell system, neural stem cells C17.2 were co-cultured with the tachyzoites of TgCtwh3 or standard type I RH strain. The apoptosis levels of C17.2 cells and the expression levels of related proteins in the endoplasmic reticulum stress (ERS)-mediated pathway were detected by flow cytometry and Western blotting.

Results: The apoptosis level of C17.2 cells co-cultured with TgCtwh3 had a significant increase compared to the negative control group; however, the apoptosis level in the TgCtwh3 group was significantly lower than that in the $\mathrm{RH}$ co-culture group. Western blotting analyses reveal that, after the C17.2 cells were co-cultured with $\mathrm{TgCtwh} 3$ and $\mathrm{RH}$ tachyzoites, the expression levels of caspase-12, CHOP and p-JNK in the cells increased significantly when compared to the control groups. After the pretreatment of Z-ATAD-FMK, an inhibitor of caspase-12, the apoptosis level of the C17.2 cells co-cultured with TgCtwh3 or RH tachyzoites had an apparent decline, and correspondingly, the expression levels of those related proteins were notably decreased.
\end{abstract}

Conclusions: Our findings suggest that TgCtwh3 may induce the apoptosis of the C17.2 cells by up-regulation of caspase-12, CHOP, and p-JNK, which are associated with ERS signaling pathways. This work contributes to better understanding the possible mechanism of brain pathology induced by T. gondii Chinese 1 isolates prevalent in China, and also reveals the potential value of ERS inhibitors to treat such related diseases in the future.

Keywords: Toxoplasma gondii, TgCtwh3, C17.2, Apoptosis

\section{Background}

Toxoplasma gondii is a ubiquitous obligate intracellular protozoan parasite that can invade almost all nucleated cells from a wide range of warm-blooded animals [1]. It is estimated that up to one-third of the human population worldwide is chronically infected with this parasite

\footnotetext{
*Correspondence: lilyyu33@126.com

${ }^{\dagger}$ Equal contributors

'Department of Microbiology and Parasitology, Anhui Provincial Laboratory of Microbiology and Parasitology, Anhui Key Laboratory of Zoonoses, Anhui Medical University, Hefei 230032, PR China

Full list of author information is available at the end of the article
}

[1,2]. In early molecular genotyping studies, $T$. gondii isolates in North America and Europe were classified into three genetic types (I, II, or III) [3-6], which vary substantially in virulence [7]. Type I strains are highly virulent to mice with an $\mathrm{LD}_{100}$ as low as a single parasite, while strains of types II and III are less virulent $\left(\mathrm{LD}_{100}>1000\right)[8,9]$. Recent population studies revealed that a few major clonal lineages of $T$. gondii dominate in different geographical regions, and the distribution of its genotype varies across the continents. The type II and III lineages are widespread in all continents, and dominate in

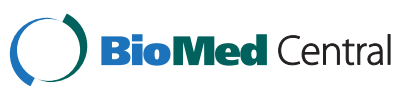

(c) 2015 Zhou et al.; licensee BioMed Central. This is an Open Access article distributed under the terms of the Creative Commons Attribution License (http://creativecommons.org/licenses/by/4.0), which permits unrestricted use, distribution, and reproduction in any medium, provided the original work is properly credited. The Creative Commons Public Domain Dedication waiver (http://creativecommons.org/publicdomain/zero/1.0/) applies to the data made available in this article, unless otherwise stated. 
Europe, Africa and North America [10,11]. The type 12 lineage is the most common type in wildlife in North America [12,13], and the Africa 1 and 3 are among the major types in Africa $[10,11,14,15]$. Unlike in North America, T. gondii in Central and South America displays a highly diverse population structure, in which no genotype appears to be clearly dominant. Chinese 1 , however, has been reported to be the most common type in East Asia, especially in China [16-20].

Significant differences in the host response to different $T$. gondii strains have been demonstrated in many previous studies. The secreted rhoptry kinase, ROP16, from types I and III, but not from type II, is involved in constitutive activation of the STAT transcription factors responsible for the alternative activation of macrophages [21,22], while the secreted dense granule protein, GRA15, from type II rather than types I and III, mediates high levels of NF- $k B$ activation, promoting the classical activation of macrophages [23-25]. A strain-dependent host response was also found in murine microglial cells [26], chicken embryonic fibroblasts [27], and human neuroepithelial cells [28].

Most of the data currently available on Toxoplasma-host cell interactions were obtained using the three archetypes I, II, and III; however, the interaction of the atypical strains with the host cells remains unknown. It is important to determine how they differ from the canonical strains in modulating the host cell, because many reports showed that some atypical strains are correlated with more severe disease manifestations [24]. TgCtwh3, a representative strain of Chinese 1 that is predominantly prevalent in China, was found to have the polymorphisms of type I ROP16 $6_{\text {I/III }}$ and type II GRA15 1 iI in our preliminary effectors sequencing analysis [29]. The features of ROP16 $6_{\mathrm{I} / \mathrm{III}}$ and GRA15 1 II TgCtwh3 suggest that it may elicit a host response which is different from the archetypical stains of Toxoplasma. As a neurotropic parasite, $T$. gondii has a strong affinity for the central nervous system, resulting in encephalitis, intracranial calcifications, hydrocephalus, etc. [30]. Our previous study revealed that the canonical type I RH strain can induce apoptosis of the neural stem cells (NSCs) through endoplasmic reticulum stress (ERS) signaling pathways [31]. To identify the signaling pathways in neural stem cells uniquely modulated by TgCtwh3, a peculiar genotype with the characteristic of canonical type I and type II, we established the co-culture system using TgCtwh3 and the neural stem cell line C17.2 to detect the apoptosis level and the expression of apoptosis-related proteins.

\section{Methods}

\section{Ethical statement}

All animal experiments were conducted in strict accordance with the Chinese National Institute of Health Guide for the Care and Use of Laboratory Animals and approved by the Institutional Review Board of Anhui Medical
University Institute of Biomedicine (Permit Number: AMU26-080610). All efforts were made to minimize animal suffering during all operational processes.

\section{Parasite}

The tachyzoites of the mouse-virulent $\mathrm{RH}$ strain (type I), TgCtwh3 (Chinese I), and GFP-RH strain (GFP-labeled $\mathrm{RH}$ strain) were harvested from the mouse peritoneal exudates on day 3 or day 5 after infection, and were then isolated by centrifugation at $350 \times \mathrm{g}$ for $5 \mathrm{~min}$ to discard the contaminating host cells. After the supernatant was centrifuged at $1000 \times \mathrm{g}$ for $10 \mathrm{~min}$, the parasites were washed twice and maintained by serial passage in the human foreskin fibroblasts (HFFs) monolayer for further experiments in vitro.

\section{Cell culture}

The C17.2 murine neural stem cell line was developed and donated by Dr. Evan Y. Snyder of the Burnham Institute for Medical Research (La Jolla, CA, USA). The cell line was cultured, as described previously [32,33]. Briefly, the cells were seeded at a density of $5 \times 10^{4}$ cells/ $\mathrm{cm}^{2}$ in $75 \mathrm{~cm}^{2}$ flasks using $10 \mathrm{ml}$ of Dulbecco's Modified Eagle Medium (DMEM; Gibco, USA), supplemented with $10 \%(\mathrm{v} / \mathrm{v})$ fetal bovine serum (Gibco, USA), 5\% $(\mathrm{v} / \mathrm{v})$ horse serum (Gibco, USA), $2 \mathrm{mM}$ l-glutamine (Gibco, USA), $100 \mathrm{U} / \mathrm{ml}$ penicillin (Sigma-Aldrich, USA) and $100 \mu \mathrm{g} / \mathrm{ml}$ streptomycin (Sigma-Aldrich, USA). The cells were incubated at $37^{\circ} \mathrm{C}$ in $5 \% \mathrm{CO}_{2}$. The medium was replaced every 2-3 days. When the cell monolayer reached $70-80 \%$ confluence, the cells were detached with a solution of $0.05 \%$ trypsin-EDTA and reseeded.

\section{Identification of C17.2 using immunofluorescence}

C17.2 cells were seeded on cover slips and cultured at $37^{\circ} \mathrm{C}$ in $5 \% \mathrm{CO}_{2}$ for $24 \mathrm{~h}$, then washed three times with PBS. Cells were fixed with $4 \%$ formaldehyde in PBS for $20 \mathrm{~min}$ at room temperature, washed with PBS, permeabilized with $0.3 \%$ Triton X-100 for $15 \mathrm{~min}$, and then blocked with $1 \%$ bovine serum albumin in PBS for $1 \mathrm{~h}$. After they were incubated with rabbit anti-Nestin monoclonal antibody (1:100; Sigma-Aldrich, USA) overnight at $4^{\circ} \mathrm{C}$, the cover slips were balanced at $37^{\circ} \mathrm{C}$ for $1 \mathrm{~h}$, washed three times with PBS, and incubated with FITCconjugated goat anti-rabbit IgG (1:200; Santa Cruz, USA) for 60 minutes at $37^{\circ} \mathrm{C}$. To observe the nucleus, cells were stained with Hoechst 33258 for $15 \mathrm{~min}$ at room temperature. Photographs were taken under a fluorescence microscope (Olympus, Japan).

\section{Establishment of C17.2 and T. gondii co-culture system and treatments}

A co-culture system was established using transwell inserts (Corning, USA), as described previously, with minor 
modification [31]. Briefly, the bottom of the inserts is composed of polyester materials with a pore size of $0.4 \mu \mathrm{m}$, which only permits the permeabilization of small and soluble factors, but not $T$. gondii tachyzoites. The permeability of the co-culture system was first verified by adding GFP-RH tachyzoites to the upper chamber, and then the green fluorescent tachyzoites were monitored in the upper and lower chambers. For the co-culture treatments, two milliliters of single cell suspension of the C17.2 cells at a density of $1 \times 10^{5} / \mathrm{ml}$ was seeded in the lower chamber of each insert. One milliliter of TgCtwh3 or RH strain tachyzoites with various doses $\left(2 \times 10^{4} / \mathrm{ml}\right.$, $1 \times 10^{5} / \mathrm{ml}$, or $5 \times 10^{5} / \mathrm{ml}$ ) was added to the upper chamber of the inserts. The co-culture system was maintained in a basic culture medium supplemented with $10 \%$ fetal bovine serum and $5 \%$ horse serum (FBS; Gibco, USA) in $5 \% \mathrm{CO}_{2}$ at $37^{\circ} \mathrm{C}$. Apopida (apoptosis inducer A; Beyotime, China) was added to the upper chamber with a dilution of 1:3000 to be used as a positive control of apoptosis. As heat-inactivation controls, tachyzoites of TgCtwh3 or RH were heated with $100^{\circ} \mathrm{C}$ for $10 \mathrm{~min}$ and then added to the upper chamber. After co-culturing for $6 \mathrm{~h}, 12 \mathrm{~h}$, and $24 \mathrm{~h}$, the C17.2 cells were collected and the apoptotic levels were detected by flow cytometry (FCM).

To investigate the activity of the ERS pathway, the C17.2 cells were pretreated with $4 \mu \mathrm{mol} / \mathrm{L}$ Z-ATADFMK (Biovision Inc., USA) for $6 \mathrm{~h}$, and then $5 \times 10^{5}$ $\mathrm{TgCtwh} 3$ or $\mathrm{RH}$ tachyzoites were added to the upper chamber. After $24 \mathrm{~h}$ incubation, the C17.2 cells were collected, the apoptotic level was detected by FCM, and the expression levels of CHOP, caspase-12, JNK, and p-JNK were detected using Western blotting.

\section{Detection of apoptosis}

The apoptotic levels of the C17.2 cells were determined following the instruction of isothiocyanate (FITC)-annexin V/propidium iodide (PI) kit (BestBio, China). Briefly, cells were harvested, washed twice with cold PBS, and resuspended in $200 \mu \mathrm{l}$ binding buffer (10 mM HEPES, 0.14 M $\mathrm{NaCl}$, and $0.25 \mathrm{mM} \mathrm{CaCl}_{2}$ ). $5 \mu \mathrm{l}$ FITC-conjugated annexin $\mathrm{V}$ was then added to the suspension and incubated at $4^{\circ} \mathrm{C}$ for $15 \mathrm{~min}$ in the dark. Next, $10 \mu \mathrm{l}$ propidium iodide (PI) was added and incubated at $4^{\circ} \mathrm{C}$ for $5 \mathrm{~min}$ in the dark. Finally, $400 \mu \mathrm{L}$ of $1 \times$ binding buffer was added to each tube. The cells were analyzed using a flow cytometer (BD FACSCalibur, USA), and the data were analyzed using FCS Express 4.0 software. Annexin V-FITC ${ }^{+} / \mathrm{PI}^{-}$cells represent the early apoptotic cells, and annexinV- $\mathrm{FITC}^{+} / \mathrm{PI}^{+}$ cells reflect the late apoptotic cells [34].

\section{Western blotting analysis}

To further identify the apoptosis of C17.2 cells, the expression levels of caspase-3, CHOP, caspase-12, p-JNK, and JNK were determined using western blotting analysis.
Western blotting was conducted as described previously [31]. Briefly, after the C17.2 cells were co-cultured with $5 \times 10^{5} \mathrm{TgCtwh} 3$ or $\mathrm{RH}$ tachyzoites for $24 \mathrm{~h}$, they were harvested, washed with cold PBS, and lysed in a lysis buffer, including $50 \mathrm{mM}$ Tris (pH 7.4), $150 \mathrm{mM} \mathrm{NaCl}, 1 \%$ Triton X-100, 1\% sodium deoxycholate, and 0.1\% SDS, supplemented with protease inhibitors and $1 \mathrm{mM}$ phenylmethanesulfonyl fluoride (PMSF). The lysates were centrifuged at $12000 \mathrm{rpm}$ for $10 \mathrm{~min}$ at $4^{\circ} \mathrm{C}$ and supernatants were collected. Protein concentrations in the supernatants were then measured using a BCA protein assay kit (Beyotime, China). Equal amounts of protein $(20 \mu \mathrm{g}$ for each sample) were separated on SDS-PAGE, and then electro-transferred onto a nitrocellulose membrane (Millipore, USA). After being rinsed in a TBST solution and blocked in 5\% non-fat milk, the membranes were subsequently probed with the antibodies of caspase-3 (1:1000; Cell Signaling Technology, USA), CHOP (1:1000; Cell Signaling Technology, USA), caspase12 (1:1000; Cell Signaling Technology, USA), phospho-cJun N-terminal kinase (p-JNK, 1:1000; Cell Signaling Technology, USA), c-Jun N-terminal kinase (JNK, 1:1000; Cell Signaling Technology, USA) or $\beta$-actin (1:1000; Cell Signaling Technology, USA) overnight at $4{ }^{\circ} \mathrm{C}$, and then incubated with a horseradish peroxidase-conjugated secondary antibody (1:5000; ZSGB-Bio, China) for $2 \mathrm{~h}$ at room temperature after being rinsed. Chemiluminescence was detected using an ECL kit (SuperSignal West Pico; Thermo Scientific, USA). The results were analyzed using Image J software (version 1.44).

\section{Statistical analysis}

All quantitative data were expressed as mean \pm SD. Student's $t$ test was used to analyze the statistical differences between two groups. Differences were considered statistically significant at a $P$ value of $<0.05$.

\section{Results}

\section{Verification of the co-culture system}

To verify the permeability of the co-culture system, GFP$\mathrm{RH}$ tachyzoites were added to the upper chamber. A large number of green fluorescent tachyzoites were found in the upper chamber under the fluorescence microscope, while no fluorescence was observed in the lower chamber (Figure 1). This indicates that Toxoplasma tachyzoites could not penetrate the filtration membrane into the lower chamber, and only excreted-secreted antigens (ESAs) of the parasite leaked into the lower chamber to exert effects on the C17.2 cells.

\section{TgCtwh3-induced apoptosis of C17.2 cells in time- and} dose-dependent manners

After the co-culture with $1 \times 10^{5}$ TgCtwh 3 tachyzoites for $6 \mathrm{~h}, 12 \mathrm{~h}$, and $24 \mathrm{~h}$, the apoptosis rate of the C17.2 

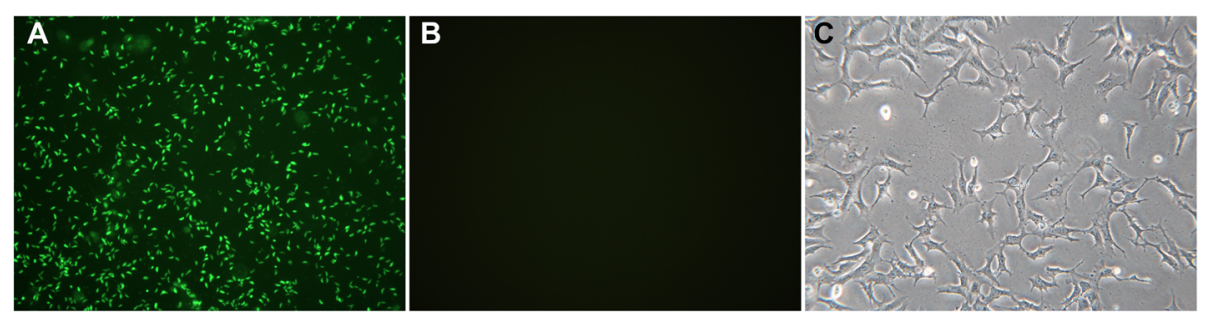

Figure 1 Detection of GFP-RH tachyzoites in co-culture system. (A) Fluorescent image of the upper chamber ( $\times 400)$; (B) fluorescent image of lower chamber (×400); (C) bright field image of the C17.2 cells in the lower chamber $(\times 200)$.

cells were $9.62 \pm 1.02 \%, 12.73 \pm 0.99 \%$, and $15.6 \pm 1.35 \%$, while the apoptosis levels in the negative controls were $4.54 \pm 1.72 \%, 5.25 \pm 1.27 \%$, and $6.98 \pm 1.11 \%$, respectively. The apoptosis rates of the heat-inactivation group were $4.99 \pm 0.54 \%, 6.29 \pm 2.08 \%$, and $7.58 \pm 1.16 \%$, respectively. Significant differences were found among the tachyzoites co-culture group, the negative control group, and the heat-inactivation group $(P<0.05)$. No significant differences were found between the heat-inactivation group and the negative control group (Figure 2A).

After the co-culture with $2 \times 10^{4}, 1 \times 10^{5}, 5 \times 10^{5}$ TgCtwh3 tachyzoites for $24 \mathrm{~h}$, the apoptosis rates of the C17.2 cells were $7.87 \pm 2.01 \%, 11.05 \pm 0.77 \%$, and $14.87 \pm$ $0.96 \%$, respectively, and statistical differences were found when they were compared to the control group of $4.8 \pm$ $1.32 \%(P<0.05)$ (Figure $2 \mathrm{~B})$. Western blotting analysis revealed that caspase- 3 of the Toxoplasma co-culture group was activated (Figure 3A). Nuclear staining showed that the nuclei of the C17.2 cells co-cultured with the Toxoplasma tachyzoites began shrinking; some nuclei appeared to have an apoptotic body (Figure 3B), which further verified the cell apoptosis.

\section{TgCtwh3 induced apoptosis of C17.2 cells via ERS pathway}

To examine whether an ERS pathway was involved in the apoptosis of the C17.2 cells induced by TgCtwh3, the cells were pretreated with $4 \mu \mathrm{mol} / \mathrm{L}$ Z-ATAD-FMK for $6 \mathrm{~h}$ before $5 \times 10^{5} \mathrm{TgCtwh} 3$ or $\mathrm{RH}$ tachyzoites were added to the upper chamber. After the pretreatment of Z-ATAD-FMK, the apoptosis rates of the C17.2 cells cocultured with TgCtwh3 tachyzoites or $\mathrm{RH}$ tachyzoites were $7.04 \pm 0.33 \%$ and $10.09 \pm 0.52 \%$, significantly lower than those in the Z-ATAD-FMK untreated TgCtwh3 group $(11.09 \pm 0.09 \%)$ and untreated $\mathrm{RH}$ group $(15.29 \pm$ $0.84 \%)$, accordingly $(P<0.05)$ (Figure 4$)$. The apoptosis rates of the C17.2 cells co-cultured with TgCtwh3 (11.09 $\pm 0.09 \%)$ were significantly lower than $\mathrm{RH}$ co-culture group (15.29 $\pm 0.84 \%$ ) (Figure 4).

Western blotting analysis further displays that the expression levels of cleaved caspase-12, CHOP, and p-JNK in the C17.2 cells increased significantly in both the TgCtwh3 and RH tachyzoites co-cultured groups when compared to the control group. When the C17.2 cells were pretreated with a caspase- 12 inhibitor, Z-ATADFMK, the expression level of cleaved caspase-12 in the inhibitor-pretreated groups significantly decreased $(P<$ $0.05)$, whereas no significant differences were detected in the levels of CHOP and p-JNK (Figure 5) when they were compared to TgCtwh3 or $\mathrm{RH}$ tachyzoites cocultured groups.

\section{Discussion}

Recent research revealed that $T$. gondii appears to have a limited genetic diversity in Asia, particularly in China. By using both PCR-RFLP and microsatellite typing, the majority of strains isolated from animals, and humans as well, belong to one lineage corresponding to the previously described ToxoDB\#9, termed as Chinese $1[11,35]$. TgCtwh3 is a representative strain of Chinese 1 , which was found to have high virulence to mice as type I RH strain [16,36]. Our previous studies revealed that TgCtwh3 shares the polymorphism of the kinase domain of ROP16 $6_{\mathrm{I} / \mathrm{III}}$ at $503 \mathrm{~L}$ with that of GT1 strain (type I), which is necessary to sustain STAT3 phosphorylation, and subsequently drive macrophages to M2 cells polarization. Additionally, TgCtwh3 has a polymorphic feature of GRA15 II (type II), which is responsible for $\mathrm{M} 1$ cells polarization. It is postulated that TgCtwh3 may induce the distinct host response and pathogenesis of toxoplasmosis, for example, toxoplasmic encephalopathy.

Apoptosis is a programmed cell death that is activated by several stimuli, including intracellular parasites. A loss of control of cell death (resulting in excess apoptosis) is involved in the pathogenesis of many infectious diseases, leading to neurodegenerative diseases, hematologic diseases, and tissue damage [37-39]. T. gondii is able to promote or inhibit the cell apoptotic machinery, depending on the host cell type, infection stage as well as its virulence and parasite load [40]. Neural stem cells (NSCs) are selfrenewing, multipotent cells that generate the main phenotype of the nervous system and play an important role in the development of the central nervous system. Previous research reported that abnormal apoptosis of the NSCs induced by congenital infection of viruses could lead to brain malformations [41-43]. Few studies have examined 


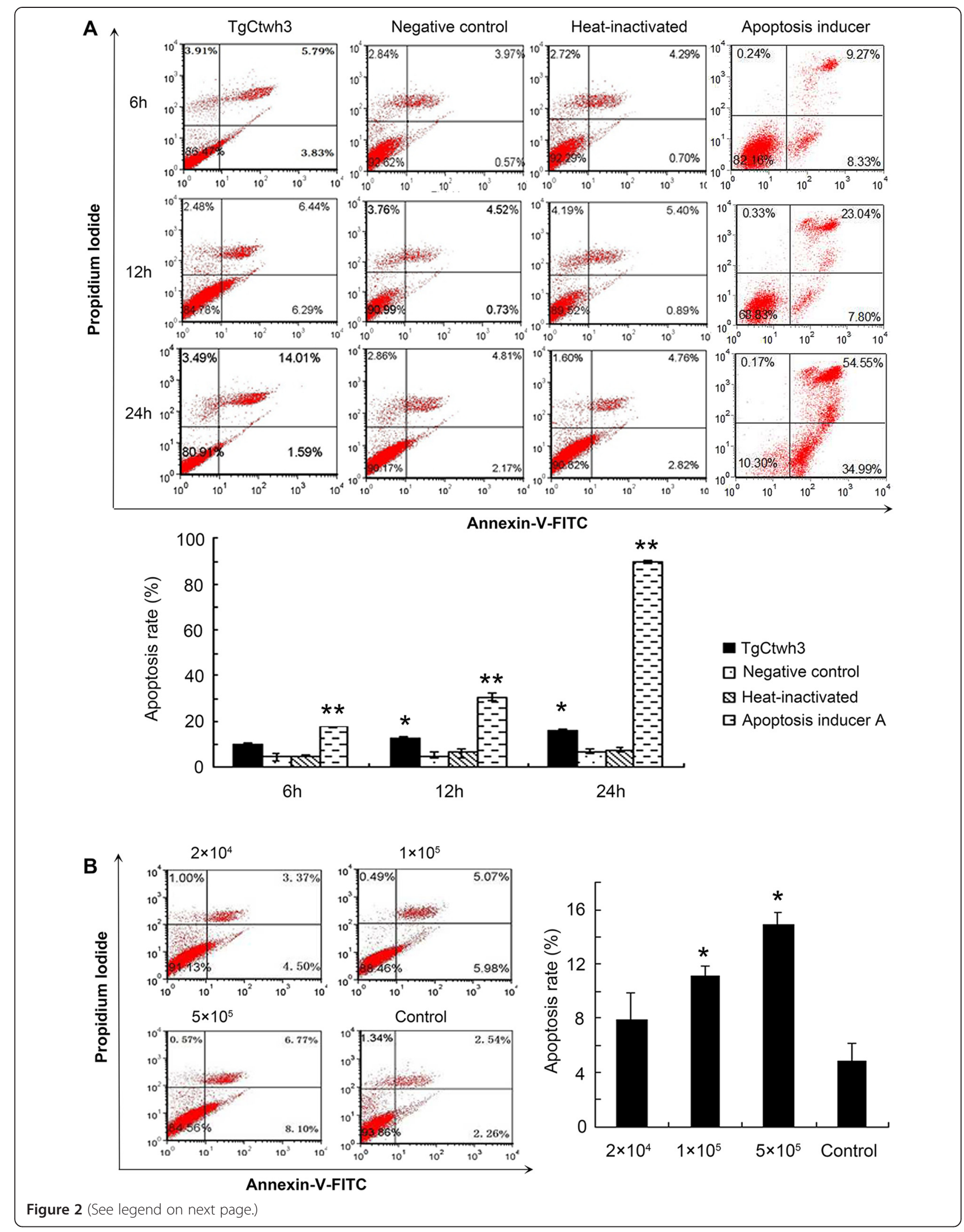


(See figure on previous page.)

Figure 2 Apoptosis detected by flow cytometry. (A) The C17.2 cells were co-cultured with $5 \times 10^{5}$ TgCtwh3 tachyzoites, heat-inactivated tachyzoites or Apopida (apoptosis inducer A) for 6 h, 12 h, and 24 h; (B) The C17.2 cells were co-cultured with various doses of TgCtwh3 tachyzoites $\left(2 \times 10^{4}, 1 \times 10^{5}\right.$ and $\left.5 \times 10^{5}\right)$ for $24 \mathrm{~h}$. The cells were then collected, stained with Annexin V/PI, and analyzed by FCM. The plots are from a representative measurement and the graphics represent the mean and S.D. on three different assays $(n=3)$. ${ }^{*} P<0.05 ;{ }^{* *} P<0.01$ vs. Negative controls.

the effect of T. gondii infection on the NSCs [31,44], in which only RH (type I) was used. In the present study, we investigated the effects of the atypical Chinese 1 strain TgCtwh3 on the neural stem cell line C17.2. The results show that TgCtwh3 induced apoptosis as early as $12 \mathrm{~h}$ after co-culture with the C17.2 cells in a dose-dependent manner (Figure 2). This differs from our previous experiments with primary NSCs of embryos of ICR mice, that showed a significant apoptosis at $24 \mathrm{~h}$ after infection with RH tachyzoites [31]. The discrepancy might be related to different Toxoplasma genotypes and different host cell types. Additionally, we found that, after the co-culture with the parasites for $24 \mathrm{~h}$, the apoptosis level of C17.2 cells induced by $\mathrm{TgCtwh} 3$ was significantly lower than that induced by $\mathrm{RH}$. The possible involvement of the background of ROP $\mathrm{I}_{\mathrm{I} / \mathrm{II}}$ and GRA15 $5_{\text {II }}$ effectors in the Chinese 1 strain remains to be elucidated.

To date, two methods are widely used to prepare ESAs of $T$. gondii. The first is to prepare the ESAs from peritoneal fluids of mice intraperitoneally infected with tachyzoites, and another is to harvest the ESAs from the supernatant of cultured tachyzoites in vitro [45-48]. Either may contain unknown components and result in an unexpected effect on the NSCs in the following experiments. Therefore, the co-culture system of the C17.2 cells and tachzoites, instead of excreted-secreted antigens (ESAs), was directly used in the present study. To test the effectiveness of this barrier system, GFP-RH tachyzoites were added to the upper chamber, and no GFP-RH tachyzoites were found in the lower chamber (Figure 1), indicating that the apoptosis of the C17.2 cells was undoubtedly induced by the ESAs of the parasite rather than the direct interaction of tachyzoites. It has been found that the major host cells could act as bystanders in acute infection, and apoptosis of the bystander host cells may result from the secretion of some soluble factors by parasite-infected cells $[49,50]$. The composition of the T. gondii ESAs is surprisingly complex, and only few microneme proteins, rhoptry proteins, and dense granule proteins have been identified [46,51]. ROP18, a major roptry effector molecule, targets the host endoplasmic reticulum-bound transcription factor ATF6beta which is involved in the apoptosis through ERS pathway [52]. The functional role of ROP18 in the apoptosis of the C17.2 cells induced by $\mathrm{TgCtwh} 3$ is under investigation.

It has been reported that apoptosis mediated by ERS pathway plays a key role in many diseases [37-39,53,54]. Our preliminary study on mouse gene expression profiling in primary NSCs infected by the RH strain indicates that the expression of some important genes involved in the ERS-induced apoptosis signal pathway were remarkably altered. To date, three apoptotic pathways triggered by ER stress have been reported. The first is the transcriptional induction of the gene for CHOP (C/EBP homologous protein)/GADD153, which is barely detected under physiological conditions, but is strongly induced in response to ER stress [55,56]. The second is the activation of the cJUN NH2-terminal kinase (JNK) pathway [57]. The third is the activation of the caspase12, which is activated by ER stress, but apparently not by death receptor-mediated or mitochondria -targeted apoptotic signals $[58,59]$. In the present study, we detected the expression levels of related proteins involved
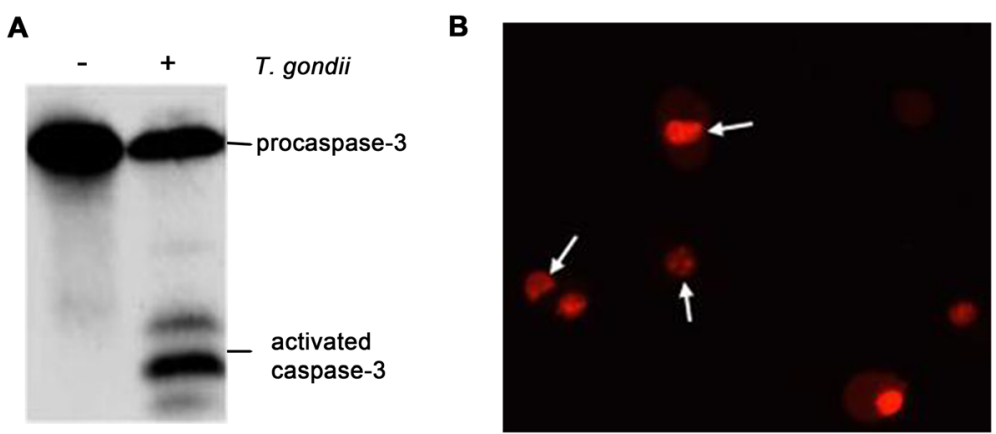

Figure 3 Apoptosis detected by Western blotting and nucleus staining. (A) The C17.2 cells were collected after they were co-cultured with $5 \times 10^{5} \mathrm{RH}$ tachyzoites for $24 \mathrm{~h}$, and the activity of caspase-3 was detected by Western blotting; (B) The nuclei of the apoptotic cells were stained by propidium iodide. The arrows represent a shrinking nucleus or apoptotic body. 


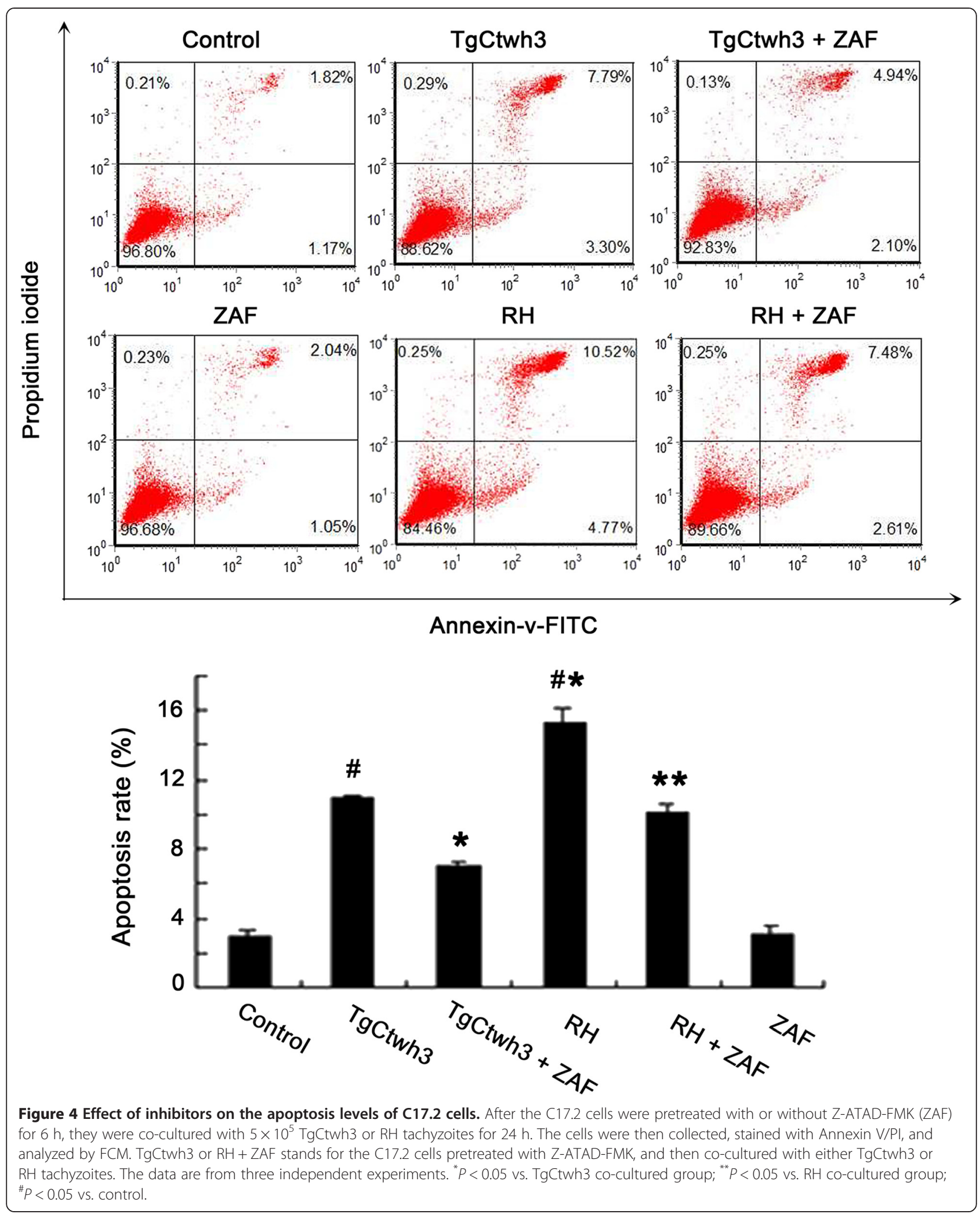



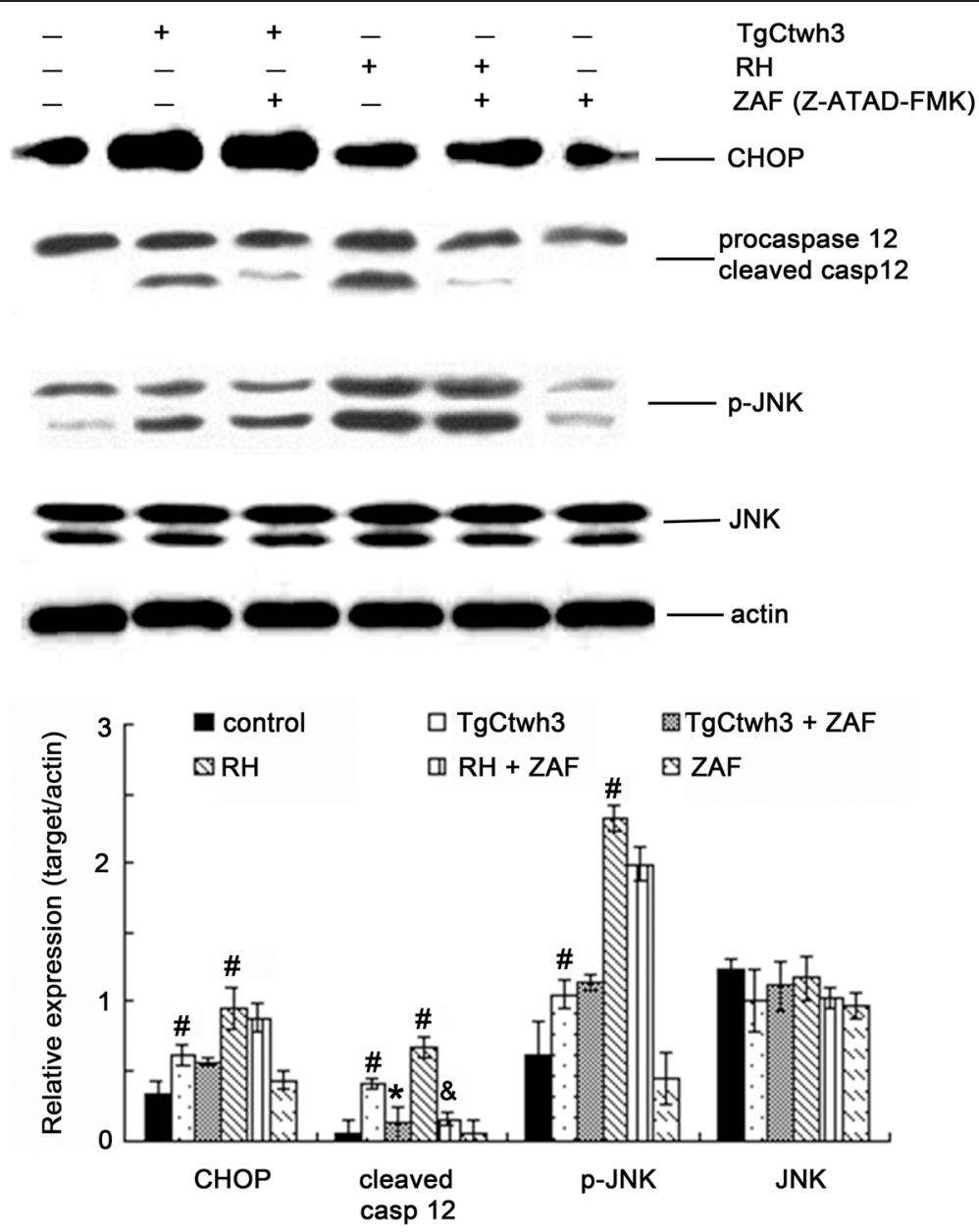

Figure 5 Expression levels of caspase-12, JNK, and CHOP in C17.2 cells. After the C17.2 cells were pretreated with or without Z-ATAD-FMK (ZAF), they were co-cultured with $5 \times 10^{5} \mathrm{TgCtwh} 3$ or $\mathrm{RH}$ tachyzoites for $24 \mathrm{~h}$. The presented figures are from a representative study and the graphics represent the mean and SD on different assays $(n=3)$. The $C 17.2$ cells without the co-culture of tachyzoites or only pretreated with ZAF were used as controls. TgCtwh3 or RH + ZAF stands for the C17.2 cells pretreated with Z-ATAD-FMK, and then co-cultured with either TgCtwh3 or $\mathrm{RH}$ tachyzoites. The experiments were repeated three times. ${ }^{\#} P<0.05$ vs. control; ${ }^{*} P<0.05$ vs. TgCtwh3 co-cultured group; \& $P<0.05$ vs. RH co-cultured group.

in the ERS-mediated apoptosis pathway in the C17.2 cells/ Toxoplasma co-culture system. Western blotting analyses show that the co-culture of both TgCtwh3 and $\mathrm{RH}$ strains up-regulated the expression levels of CHOP, activated caspase-12, and p-JNK in the C17.2 cells. Meanwhile, the caspase-12 inhibitor Z-ATAD-FMK reduced the apoptosis induced by TgCtwh3. These results were consistent with our previous data found in primary NSCs infected by $\mathrm{RH}$ tachyzoites, indicating that both TgCtwh3 and RH strains induced the apoptosis of NSC cell line or primary NSCs through the ERS pathway.

\section{Conclusions}

The ESAs of TgCtwh3, a representative strain of type Chinese 1 mostly found in China, induced the apoptosis of the C17.2 cells as early as $12 \mathrm{~h}$ after co-culture. The
ESAs derived from both TgCtwh3 and $\mathrm{RH}$ induced C17.2 cells apoptosis via ERS signaling pathways but TgCtwh3 is a lower inducer than the RH strain. Our findings contribute to better understanding the possible mechanism of brain pathology caused by $T$. gondii prevalent in China, and also reveal the potential value of ERS inhibitors in treatment strategy of Toxoplasmic encephalopathy.

\section{Competing interests}

The authors declare that they have no competing interests.

\section{Authors' contributions}

$L Y, J S$ and $Y W$ conceived and designed the study, and critically revised the manuscript. $L Y, J Z, X G, X Z$ and $X D$ performed the experiments, analyzed the data and drafted the manuscript. LY, YW, LC, JD, QL and TW participated in the analysis and interpretation of data. All authors have read and approved the final manuscript. 


\section{Acknowledgements}

This work was supported by Natural Science Foundation of China (J. S., No. 81471983), (L.Y., No. 30800965), (J.D., No. 81271864); the National Basic Research Program of China (J. S., No. 2010CB530001); and the Outstanding Young Scholars Financial Support of Anhui Medical University (L.Y., No.0113014104)

\section{Author details}

${ }^{1}$ Department of Microbiology and Parasitology, Anhui Provincial Laboratory of Microbiology and Parasitology, Anhui Key Laboratory of Zoonoses, Anhui Medical University, Hefei 230032, PR China. ${ }^{2}$ Clinical Laboratory, People's Hospital of Huaibei, Huaibei 235000, PR China. ${ }^{3}$ College of Life Sciences, Zhejiang Sci-Tech University, Hangzhou 310018, PR China. ${ }^{4}$ School of Life Sciences, Anhui University, Hefei 230039, PR China. ${ }^{5}$ Department of Biochemistry, Anhui Medical University, Hefei 230032, PR China. ${ }^{6}$ HTS \& Compound Management, HD Biosciences Corporation, Shanghai 201201, PR China.

\section{Received: 7 September 2014 Accepted: 18 January 2015} Published online: 04 February 2015

\section{References}

1. Dubey JP. Toxoplasmosis of animals and humans. 2nd ed. CRC Press; 2010.

2. Tenter AM, Heckeroth AR, Weiss LM. Toxoplasma gondii: from animals to humans. Int J Parasitol. 2000;30:1217-58.

3. Howe DK, Sibley LD. Toxoplasma gondii comprises three clonal lineages: correlation of parasite genotype with human disease. J Infect Dis. 1995;172:1561-6.

4. Howe DK, Honore S, Derouin F, Sibley LD. Determination of genotypes of Toxoplasma gondii strains isolated from patients with toxoplasmosis. J Clin Microbiol. 1997:35:1411-4.

5. Darde ML, Bouteille B, Pestre-Alexandre M. Isoenzyme analysis of 35 Toxoplasma gondii isolates and the biological and epidemiological implications. J Parasitol. 1992;78:786-94.

6. Ajzenberg D, Banuls AL, Tibayrenc M, Darde ML. Microsatellite analysis of Toxoplasma gondii shows considerable polymorphism structured into two main clonal groups. Int J Parasitol. 2002:32:27-38.

7. Saeij JP, Boyle JP, Boothroyd JC. Differences among the three major strains of Toxoplasma gondii and their specific interactions with the infected host. Trends Parasitol. 2005;21:476-81.

8. Sibley LD, Boothroyd JC. Virulent strains of Toxoplasma gondii comprise a single clonal lineage. Nature. 1992;359:82-5.

9. Sibley LD, Khan A, Ajioka JW, Rosenthal BM. Genetic diversity of Toxoplasma gondii in animals and humans. Philos Trans R Soc Lond B Biol Sci. 2009;364:2749-61.

10. Rajendran C, Su C, Dubey JP. Molecular genotyping of Toxoplasma gondii from Central and South America revealed high diversity within and between populations. Infect Genet Evol. 2012;12:359-68.

11. Shwab EK, Zhu XQ, Majumdar D, Pena HF, Gennari SM, Dubey JP, et al. Geographical patterns of Toxoplasma gondii genetic diversity revealed by multilocus PCR-RFLP genotyping. Parasitology. 2014;141:453-61.

12. Dubey JP, Velmurugan GV, Rajendran C, Yabsley MJ, Thomas NJ, Beckmen $K B$, et al. Genetic characterisation of Toxoplasma gondii in wildlife from North America revealed widespread and high prevalence of the fourth clonal type. Int J Parasitol. 2011;41:1139-47.

13. Khan A, Dubey JP, Su C, Ajioka JW, Rosenthal BM, Sibley LD. Genetic analyses of atypical Toxoplasma gondii strains reveal a fourth clonal lineage in North America. Int J Parasitol. 2011;41:645-55.

14. Mercier A, Devillard S, Ngoubangoye B, Bonnabau H, Banuls AL, Durand P, et al. Additional haplogroups of Toxoplasma gondii out of Africa: population structure and mouse-virulence of strains from Gabon. PLoS Negl Trop Dis. 2010;4:e876.

15. Al-Kappany YM, Rajendran C, Abu-Elwafa SA, Hilali M, Su C, Dubey JP. Genetic diversity of Toxoplasma gondii isolates in Egyptian feral cats reveals new genotypes. J Parasitol. 2010;96:1112-4.

16. Wang L, Chen H, Liu D, Huo X, Gao J, Song X, et al. Genotypes and mouse virulence of Toxoplasma gondii isolates from animals and humans in China. PLoS One. 2013:8:e53483.

17. Zhou P, Nie H, Zhang LX, Wang HY, Yin CC, Su C, et al. Genetic characterization of Toxoplasma gondii isolates from pigs in China. J Parasitol. 2010;96:1027-9.
18. Zhou P, Sun XT, Yin CC, Yang JF, Yuan ZG, Yan HK, et al. Genetic characterization of Toxoplasma gondii isolates from pigs in southwestern China. J Parasitol. 2011;97:1193-5.

19. Chen ZW, Gao JM, Huo XX, Wang L, Yu L, Halm-Lai F, et al. Genotyping of Toxoplasma gondii isolates from cats in different geographic regions of China. Vet Parasitol. 2011;183(1-2):166-70.

20. Li M, Mo XW, Wang L, Chen H, Luo QL, Wen HQ, et al. Phylogeny and virulence divergency analyses of Toxoplasma gondii isolates from China. Parasit Vectors. 2014;7:133.

21. Butcher BA, Fox BA, Rommereim LM, Kim SG, Maurer KJ, Yarovinsky F, et al. Toxoplasma gondii Rhoptry Kinase ROP16 activates STAT3 and STAT6 resulting in cytokine inhibition and arginase-1-dependent growth control. PLoS Pathog. 2011;7:e1002236.

22. Saeij JP, Coller S, Boyle JP, Jerome ME, White MW, Boothroyd JC. Toxoplasma co-opts host gene expression by injection of a polymorphic kinase homologue. Nature. 2007;445:324-7.

23. Jensen KD, Wang Y, Wojno ED, Shastri AJ, Hu K, Cornel L, et al. Toxoplasma polymorphic effectors determine macrophage polarization and intestina inflammation. Cell Host Microbe. 2011;9:472-83.

24. Melo MB, Nguyen QP, Cordeiro C, Hassan MA, Yang N, McKell R, et al. Transcriptional analysis of murine macrophages infected with different Toxoplasma strains identifies novel regulation of host signaling pathways. PLoS Pathog. 2013:9:e1003779.

25. Rosowski EE, Lu DN, Julien L, Rodda L, Gaiser RA, Jensen KDC, et al. Strainspecific activation of the NF-kappa B pathway by GRA15, a novel Toxoplasma gondii dense granule protein. J Exp Med. 2011;208:195-212.

26. Glaser KC, Hagos B, Molestina RE. Effects of Toxoplasma gondii genotype and absence of host MAL/Myd88 on the temporal regulation of gene expression in infected microglial cells. Exp Parasitol. 2011;129:409-13.

27. Ong YC, Boyle JP, Boothroyd JC. Strain-dependent host transcriptional responses to Toxoplasma infection are largely conserved in mammalian and avian hosts. PLoS One. 2011;6:e26369.

28. Xiao J, Jones-Brando L, Talbot Jr CC, Yolken RH. Differential effects of three canonical Toxoplasma strains on gene expression in human neuroepithelial cells. Infect Immun. 2011;79:1363-73.

29. Cai Y, Chen H, Mo X, Tang Y, Xu X, Zhang A, et al. Toxoplasma gondii inhibits apoptosis via a novel STAT3-miR-17-92-Bim pathway in macrophages. Cell Signal. 2014;26:1204-12.

30. Petersen E. Toxoplasmosis. Semin Fetal Neonatal Med. 2007;12:214-23.

31. Wang T, Zhou J, Gan X, Wang H, Ding X, Chen L, et al. Toxoplasma gondi induce apoptosis of neural stem cells via endoplasmic reticulum stress pathway. Parasitology. 2014;141:988-95.

32. Rocha RA, Gimeno-Alcaniz JV, Martin-Ibanez R, Canals JM, Velez D, Devesa V. Arsenic and fluoride induce neural progenitor cell apoptosis. Toxicol Lett. 2011;203:237-44.

33. Doering LC, Snyder EY. Cholinergic expression by a neural stem cell line grafted to the adult medial septum/diagonal band complex. J Neurosci Res. 2000;61:597-604

34. Fang Y, Yu S, Ellis JS, Sharav T, Braley-Mullen H. Comparison of sensitivity of Th1, Th2, and Th17 cells to Fas-mediated apoptosis. J Leukoc Biol. 2010:87:1019-28

35. Wang L, Cheng HW, Huang KQ, Xu YH, Li YN, Du J, et al. Toxoplasma gondii prevalence in food animals and rodents in different regions of China: isolation, genotyping and mouse pathogenicity. Parasit Vectors. 2013;6:273.

36. Zhang AM, Shen Q, Li M, Xu XC, Chen H, Cai YH, et al. Comparative studies of macrophage-biased responses in mice to infection with Toxoplasma gondii ToxoDB \#9 strains of different virulence isolated from China. Parasit Vectors. 2013:6:308.

37. Omura T, Kaneko M, Okuma Y, Orba Y, Nagashima K, Takahashi R, et al. A ubiquitin ligase HRD1 promotes the degradation of Pael receptor, a substrate of Parkin. J Neurochem. 2006;99:1456-69.

38. Gao B, Lee SM, Chen A, Zhang J, Zhang DD, Kannan K, et al. Synoviolin promotes IRE1 ubiquitination and degradation in synovial fibroblasts from mice with collagen-induced arthritis. EMBO Rep. 2008:9:480-5.

39. Amano T, Yamasaki S, Yagishita N, Tsuchimochi K, Shin H, Kawahara K, et al. Synoviolin/Hrd1, an E3 ubiquitin ligase, as a novel pathogenic factor for arthropathy. Genes Dev. 2003;17:2436-49.

40. Contreras-Ochoa CO, Lagunas-Martinez A, Belkind-Gerson J, Diaz-Chavez J, Correa D. Toxoplasma gondii invasion and replication within neonate mouse astrocytes and changes in apoptosis related molecules. Exp Parasitol. 2013;134:256-65. 
41. Sun X, Guan Y, Li F, Li X, Wang X, Guan Z, et al. Effects of rat cytomegalovirus on the nervous system of the early rat embryo. Virol $\mathrm{Sin}$. 2012;27:234-40.

42. D'Aiuto L, Di Maio R, Heath B, Raimondi G, Milosevic J, Watson AM, et al. Human induced pluripotent stem cell-derived models to investigate human cytomegalovirus infection in neural cells. PLoS One. 2012;7:e49700.

43. Mutnal MB, Cheeran MC, Hu S, Lokensgard JR. Murine cytomegalovirus infection of neural stem cells alters neurogenesis in the developing brain. PLoS One. 2011;6:e16211.

44. Sun XN, Liu ZJ, Guan ZY, Liang RW, Zhang HY, Wu XY, et al. Effect of Toxoplasma gondii infection on the embryonic neural stem cells in rats. Zhongguo Ji Sheng Chong Xue Yu Ji Sheng Chong Bing Za Zhi. 2012:30:253-7

45. Chen JL, Ge YY, Zhang J, Qiu XY, Qiu JF, Wu JP, et al. The dysfunction of CD4(+)CD25(+) regulatory $T$ cells contributes to the abortion of mice caused by Toxoplasma gondii excreted-secreted antigens in early pregnancy. PLoS One. 2013;8:e69012.

46. Gladkova SE, Bormotov NI, Dedkova LM, Reshetnikov SS, Kurlaeva TB, Belanov EF. An immunochemical study of the antigens from Toxoplasma gondii tachyzoites obtained in different cultivation systems. Med Parazitol (Mosk). 1998:1:20-3.

47. Abdollahi SO, Arababadi MK, Hassanshahi G. Evaluation of excreted/secreted antigens derived from peritoneal of toxoplasma infected small mice to detect lgG against Toxoplasma. Pak J Biol Sci. 2009;12:530-3.

48. Costa-Silva TA, Borges MM, Galhardo CS, Pereira-Chioccola VL. Immunization with excreted/secreted proteins in AS/n mice activating cellular and humoral response against Toxoplasma gondii infection. Acta Trop. 2012;124:203-9.

49. Nishikawa Y, Kawase O, Vielemeyer O, Suzuki H, Joiner KA, Xuan X, et al. Toxoplasma gondii infection induces apoptosis in noninfected macrophages: role of nitric oxide and other soluble factors. Parasite Immunol. 2007:29:375-85.

50. Mordue DG, Monroy F, La Regina M, Dinarello CA, Sibley LD. Acute toxoplasmosis leads to lethal overproduction of Th1 cytokines. J Immunol. 2001;167:4574-84.

51. Zhou XW, Kafsack BF, Cole RN, Beckett P, Shen RF, Carruthers VB. The opportunistic pathogen Toxoplasma gondii deploys a diverse legion of invasion and survival proteins. J Biol Chem. 2005;280:34233-44.

52. Yamamoto M, Ma JS, Mueller C, Kamiyama N, Saiga H, Kubo E, et al. ATF6beta is a host cellular target of the Toxoplasma gondii virulence factor ROP18. J Exp Med. 2011;208:1533-46.

53. Lei X, Zhang S, Barbour SE, Bohrer A, Ford EL, Koizumi A, et al. Spontaneous development of endoplasmic reticulum stress that can lead to diabetes mellitus is associated with higher calcium-independent phospholipase A2 expression: a role for regulation by SREBP-1. J Biol Chem. 2010;285:6693-705

54. Allen JR, Nguyen LX, Sargent KE, Lipson KL, Hackett A, Urano F. High ER stress in beta-cells stimulates intracellular degradation of misfolded insulin. Biochem Biophys Res Commun. 2004;324:166-70.

55. Wang XZ, Lawson B, Brewer JW, Zinszner H, Sanjay A, Mi LJ, et al. Signals from the stressed endoplasmic reticulum induce C/EBP-homologous protein (CHOP/GADD153). Mol Cell Biol. 1996;16:4273-80.

56. Ron D, Habener JF. CHOP, a novel developmentally regulated nuclear protein that dimerizes with transcription factors C/EBP and LAP and functions as a dominant-negative inhibitor of gene transcription. Genes Dev. 1992;6:439-53.

57. Urano $F$, Wang $X$, Bertolotti $A$, Zhang $Y$, Chung $P$, Harding HP, et al. Coupling of stress in the ER to activation of JNK protein kinases by transmembrane protein kinase IRE1. Science. 2000;287:664-6.

58. Nakagawa T, Zhu H, Morishima N, Li E, Xu J, Yankner BA, et al. Caspase-12 mediates endoplasmic-reticulum-specific apoptosis and cytotoxicity by amyloid-beta. Nature. 2000;403:98-103.

59. Araki E, Oyadomari S, Mori M. Endoplasmic reticulum stress and diabetes mellitus. Intern Med. 2003:42:7-14.

\section{Submit your next manuscript to BioMed Central and take full advantage of:}

- Convenient online submission

- Thorough peer review

- No space constraints or color figure charges

- Immediate publication on acceptance

- Inclusion in PubMed, CAS, Scopus and Google Scholar

- Research which is freely available for redistribution

Submit your manuscript at www.biomedcentral.com/submit 